\title{
A prospective study on clinico-epidemiological profile and outcome in management of poisonous snake bite
}

\author{
Mukesh Kumar Chaudhary*, Laxmi K. Gupta, Lokendra B. Chand, \\ Ramesh Chaudhary, Sabin Ranpal
}

Department of Pharmacy, Crimson College of Technology, Butwal-11, Rupandehi, Nepal

Received: 24 February 2020

Revised: 04 April 2020

Accepted: 07 April 2020

*Correspondence:

Mr. Mukesh Kumar Chaudhary,

Email: pharmatext@yahoo.com

Copyright: (C) the author(s), publisher and licensee Medip Academy. This is an open-access article distributed under the terms of the Creative Commons Attribution Non-Commercial License, which permits unrestricted non-commercial use, distribution, and reproduction in any medium, provided the original work is properly cited.

\begin{abstract}
Background: Snake bite is a major health problem in Nepal. According to WHO, annual morbidity due to snake bite is 162 out of 100,000 people in Nepal. Aim of the study is to observe epidemiology, clinical features, and analysis of possible relationship between time delay in administration of anti-snake venom (ASV) and mortality.

Methods: This prospective observational study analyses the data of 81 patients admitted to the Lumbini zonal hospital, Butwal, Rupandehi, Nepal with history of snake bite between April to September, 2017.

Results: In this study 56\% patients were female. Patients of age group (15-30) years were maximum (38.27\%). The study showed that $50.61 \%$ of snake bites were occurred outside home. Most of patients $(84 \%)$ were from the Terai region. Average no. of vials used per case was $(28 \pm 10)$ vials. Most of victims of snake bite were from rural areas. In most of cases we found that prothrombin time was prolonged. It was found that most of patients $57 \%$ reach hospital before 4 hours of snake bite. The mean days of hospital stay was $6 \pm 2.86$. Most of case of snake bite was unknown (62\%). The mortality rate in this study was $6.17 \%$.

Conclusions: There is a great need to improve in existing health care conditions for effective management of snake bite; it requires training of the personnel engaged in the emergency health care management, development of national guidelines based on the clinical trials, improving the distribution and easy availability of antivenom.
\end{abstract}

Keywords: Anti-snake venom, Krait, Poisonous snake, Snake bite

\section{INTRODUCTION}

Snake bite is a common medical emergency and major cause of hospital admissions. Snake bite is a lifethreatening emergency and a high incidence of snake bite envenomation is reported from rural area. But due to inadequate epidemiological data the incidence is underestimated. Snakebite is an environmental hazard associated with significant morbidity and mortality. ${ }^{1}$ When a person is bitten by a poisonous snake, venom is injected, causing localized symptoms of mild pain and edema and generalized ones including dyspnea, ptosis, mental alteration, and tachycardia. In severe cases, patients develop acute renal failure, myocardial infarction, disseminated intravascular coagulation, and even death. ${ }^{2}$ Treatment for poisonous snakebite is divided into supportive care and antivenom administration. Krait venom blocks both the pre and post synaptic receptors and need prolonged mechanical respiration until their receptors are regenerated. Cobra venom blocks the post synaptic receptors and needs more ASV and neostigmine. ${ }^{3}$ The oral flora of snake comprises a wide range of aerobic and anaerobic micro-organisms, especially the fecal Gram-negative rods, because their prey usually defecates while being ingested. Culture of 
fangs, fang sheaths, and venom of various snakes such as vipers, rattle snakes and Naja, have shown heavy colonization with many bacteria, including members of Enterobacteriaceae including Morganella spp. and Escherichia coli, Group D streptococci, Aeromonas spp. and anaerobes such as Clostridium spp. so antibiotics were also used in treatment. ${ }^{4}$ Time delay between the snake bite envenomation and initiation of treatment with ASV has a great bearing on mortality rate. If the ASV treatment is initiated within 12 hours the mortality rate may be $2.6 \%$ and if it is more than 24 hours the mortality rate will be around $13.5 \%$. Immediate and rapid transport of victims to a treatment center by motor cycle volunteers decreased the mortality rate and incidence of snakebite in southeastern Nepal. ${ }^{5}$

\section{Rationale of study}

Since ancient times, snakes have been worshipped, feared, or loathed. Unfortunately, snakes remain a painful reality in the daily life of millions of villagers. Indeed, although anti-venom is produced in sufficient quantities by several public and private manufacturers, most snake bite victims don't have access to quality care due to this reason both morbidity and mortality due to snake bites are high. ${ }^{6}$ Nepal is an agriculture based country which has vast agriculturally fertile Terai region with the hot climate and high seasonal rainfall. It also has high density of rodents, reptiles and amphibians flora which makes it an ideal habitat for snake to live and hibernate. Snake bite is an important occupational injury affecting farmers, plantation, workers, herders, fisherman, and snake restaurant workers. Open style habitation and practice of sleeping on the floor also expose to bite from nocturnal snake. It results in death or chronic disability to many persons of active younger age. ${ }^{7}$ Snake bite has high fatality due to various factor. There is a lack of public awareness, education, wide spread myths and superstition regarding snake bite which restricts patient in seeking proper treatment in anti-snake venom treatment center. Large number of patient's firsts go to traditional healers which leads to important significant delays in getting timely treatment. ${ }^{8}$ There is a number of victims who die after reaching the hospital because of inadequate treatment due to poor health infrastructure, wide species variation. Limited species of anti-snake venom, inexperience in handling such cases, unavailability of ventilator and work compliance with treatment protocols. Snake bite which is major cause of death in rural patients in developing countries, is neglected public health problem. Its incidence is usually underestimated because of lack of epidemiological data and therefore this study mainly focuses on clinico-epidemiological profile and outcome in management of poisonous snake bite.

\section{Objectives}

To study the clinico-epidemiological profile and outcome in management of poisonous snake bite and analysis of possible relationship between time delay in administration of anti-snake venom and mortality.

\section{METHODS}

\section{Study type}

A prospective observational study was conducted for 6 months (April to September, 2017).

\section{Study site}

The study was conducted at Lumbini Zonal Hospital, Butwal, Rupandehi, Nepal. The data were taken from the in-patients who were visited to the hospital for the treatment of different snake bite cases during the study period.

\section{Inclusion criteria}

Inclusion criteria were male and female patients of any age.

\section{Exclusion criteria}

Exclusion criteria were those patients, who came with history of snakebite, but no definite fang marks and no symptoms, signs or evidence. Those patients were bitten by nonpoisonous snake or some other animals.

\section{Study material}

Patient profile form with details like name, age, sex, weight, address, economic status, occupation, site of bite, place of bite, date and time of bite, date of admission, name of snake bite, symptoms, first aid, laboratory data, therapy, discharge date, etc. Provision is given in the format to enter laboratory investigations, diagnosis made and number of drugs prescribed.

\section{Statistical tool}

The data recorded in encounter form was entered in microsoft excel 2013, SPSS and analyzed different parameters like mean, $\pm \mathrm{SD}$.

\section{RESULTS}

All together 81 patients were included in this study. The highest incidence of snake bite was observed in patients with ages between (15-29) years followed by (30-44) years. The mean age of patients in our study was $(30 \pm 18)$ years. Among them 36 were males and 45 were females. Maximum incidence of snake bites was in rural areas (91\%). About $84 \%$ were from Terai regions. Most of bite occurs during outdoor activities (51.61). The bite occurs in lower limb $(59.25 \%)$ in maximum cases. About $82.71 \%$ of patients uses tourniquet as first aid. 
Table 1: Demographic profile of patients with snake bite.

\begin{tabular}{|c|c|c|c|c|}
\hline \multicolumn{3}{|c|}{ S. no. } & \multirow{2}{*}{$\begin{array}{l}\text { Number of patients }(\mathrm{n}=\mathbf{8 1}) \\
15\end{array}$} & \multirow{2}{*}{$\begin{array}{l}\% \text { of patients } \\
18.51\end{array}$} \\
\hline \multirow{5}{*}{1} & \multirow{5}{*}{ Age (in years) } & $0-15$ & & \\
\hline & & $15-30$ & 31 & 38.27 \\
\hline & & $30-45$ & 19 & 23.45 \\
\hline & & $45-60$ & 9 & 11.11 \\
\hline & & $>60$ & 7 & 8.64 \\
\hline \multirow{2}{*}{2} & \multirow{2}{*}{ Sex } & Male & 36 & 44.44 \\
\hline & & Female & 45 & 55.55 \\
\hline \multirow{2}{*}{3} & \multirow{2}{*}{ Area } & Rural & 74 & 91 \\
\hline & & Urban & 7 & 9 \\
\hline \multirow{2}{*}{4} & \multirow{2}{*}{ Geographical regions } & Terai & 68 & 84 \\
\hline & & Hilly & 13 & 16 \\
\hline \multirow{2}{*}{5} & \multirow{2}{*}{ Place of bite } & Inside home & 40 & 49.38 \\
\hline & & Outside home & 41 & 50.61 \\
\hline \multirow{3}{*}{6} & \multirow{3}{*}{ Site of bite } & Upper limb & 22 & 27.16 \\
\hline & & Lower limb & 48 & 59.25 \\
\hline & & Others & 11 & 13.58 \\
\hline \multirow{4}{*}{7} & \multirow{4}{*}{ Type of first aid used } & Tourniquet & 67 & 82.71 \\
\hline & & Sucking of blood & 3 & 3.7 \\
\hline & & Dhami/Jhakari & 4 & 4.9 \\
\hline & & No any first aid & 7 & 8.64 \\
\hline \multirow{3}{*}{8} & \multirow{3}{*}{ Economic status } & Low & 52 & 64.20 \\
\hline & & Medium & 29 & 35.80 \\
\hline & & High & 0 & 0 \\
\hline \multirow{4}{*}{9} & \multirow{4}{*}{ Name of snake bite } & Krait & 23 & 28.39 \\
\hline & & Cobra & 4 & 4.93 \\
\hline & & Viper & 4 & 4.93 \\
\hline & & Unknown & 50 & 61.72 \\
\hline
\end{tabular}

Table 2: Clinical profile and outcome of snake bite patients.

\begin{tabular}{|c|c|c|c|c|}
\hline S. no. & & & Number of patients $(\mathrm{n}=\mathbf{8 1})$ & $\%$ of patients \\
\hline \multirow{15}{*}{1} & \multirow{15}{*}{ Sign and symptoms } & Pain & 81 & 100 \\
\hline & & Bleeding & 8 & 9.81 \\
\hline & & Ptosis & 78 & 96.29 \\
\hline & & Salvation & 23 & 28.39 \\
\hline & & Hemoptysis & 3 & 3.70 \\
\hline & & Blurred vision & 45 & 55.55 \\
\hline & & Dysphonia & 49 & 60.49 \\
\hline & & Swelling & 40 & 49.38 \\
\hline & & Dysphagia & 41 & 50.61 \\
\hline & & Sweating & 20 & 24.69 \\
\hline & & Vomiting & 52 & 64.19 \\
\hline & & Respiratory distress & 61 & 75.30 \\
\hline & & Paralysis & 5 & 6.17 \\
\hline & & Dry mouth & 12 & 14.81 \\
\hline & & Faint & 2 & 2.46 \\
\hline \multirow{6}{*}{2} & \multirow{6}{*}{ No of ASV vials used } & $>10$ & 3 & 3.70 \\
\hline & & $10-20$ & 10 & 12.34 \\
\hline & & $20-30$ & 39 & 48.14 \\
\hline & & $30-40$ & 25 & 30.86 \\
\hline & & $40-50$ & 3 & 3.7 \\
\hline & & $<50$ & 1 & 1.23 \\
\hline
\end{tabular}




\begin{tabular}{|c|c|c|c|c|}
\hline \multicolumn{3}{|c|}{ S. no. } & \multirow{2}{*}{$\begin{array}{l}\text { Number of patients }(\mathbf{n}=\mathbf{8 1}) \\
46\end{array}$} & \multirow{2}{*}{$\begin{array}{l}\% \text { of patients } \\
56.79\end{array}$} \\
\hline & \multirow{5}{*}{$\begin{array}{l}\text { Time to reach hospital } \\
\text { after bite }\end{array}$} & $<4$ hours & & \\
\hline \multirow{4}{*}{3} & & 4-8 hours & 16 & 19.75 \\
\hline & & $8-12$ hours & 7 & 8.64 \\
\hline & & $12-16$ hours & 6 & 7.40 \\
\hline & & $>16$ hours & 6 & 7.40 \\
\hline \multirow{6}{*}{4} & \multirow{6}{*}{ Prothrombin time } & $\leq 19$ & 23 & 29 \\
\hline & & $20-40$ & 36 & 46 \\
\hline & & $40-60$ & 8 & 10 \\
\hline & & $60-80$ & 0 & 0 \\
\hline & & $80-100$ & 0 & 0 \\
\hline & & $\geq 100$ & 12 & 15 \\
\hline \multirow{5}{*}{5} & \multirow{5}{*}{ Day of hospital stay } & $<2$ & 5 & 6 \\
\hline & & $2-6$ & 30 & 37 \\
\hline & & $6-10$ & 36 & 44 \\
\hline & & $10-14$ & 7 & 9 \\
\hline & & $>14$ & 3 & 4 \\
\hline \multirow{2}{*}{6} & \multirow{2}{*}{ Outcome } & Recovered & 76 & 93.82 \\
\hline & & Death & 5 & 6.17 \\
\hline
\end{tabular}

The highest number (52) of patients belongs to low economic status. The demographic profile of patients is given in (Table 1).

In this study pain $(100 \%)$ was the most common clinical presentation followed by ptosis $(96.29 \%)$ and respiratory distress $(75.30 \%)$. The most of the patients $(48.14 \%)$ was treated with 20-29 vials of ASV. The mean and SD of ASV vials used in patients was $28 \pm 10$. Near about $56.79 \%$ of patients reach hospital after 3 hours of bite and $7.40 \%$ of patients after more than 16 hours of bite. $46 \%$ of patient shows prolongation of prothrombin time between 20-39 second and $15 \%$ of patient shows prolongation of prothrombin time more than 100 second. The maximum days of hospital stay was in between (6-9) days (44\%) followed by $2-5$ days (37\%). Out of 81 patients 76 recovered and 5 patients died. The clinical profile and outcome of snake bite patients is given in (Table 2).

\section{DISCUSSION}

During our study, we collected 297 cases of snake bite. Out of them 212 patient cases were nonpoisonous and 85 cases were poisonous bite. Out of 85 patient cases 4 cases were referred to other hospital, so we included 81 poisonous snake bite cases in this study. In this study (1444) years age group was the most commonly bitten age group, which was $61.72 \%$. Other studies also reported similar type of observations. ${ }^{9,10}$ This may be due to (15$45)$ years age group is the most active in various outdoor an indoor occupation.

In our study, females $(55.55 \%)$ were more prone to snake bite compared to males $(44.44 \%)$. Other study also supported this observation. ${ }^{11,12}$ However this finding was opposite to many other studies., ${ }^{3,5,13}$ In this study, incidence of snake bite was found more in rural area $(91 \%)$ and least from urban area (9\%). This finding was similar to other study..$^{3,7,9,14}$ Dwelling conditions in rural areas of Nepal is more favorable for habitation of snakes and most people are engaged in agriculture work, which leads to more snake bites. Most patients visited are from Terai regions $(84 \%)$ compared to hilly regions $(16 \%)$. It is because due to Terai region's climate is more favorable for snake habitat. The incidence of snake bite is high in warmer regions where snakes are found abundantly and agriculture is the main occupation. In Nepal it is estimated that at least 1000 death occurs due to snake bite in Terai region each year. ${ }^{9}$ Out of 81 patients, inside home and outside shows almost similar number of snake bite.

In this study, $59.25 \%$ of bites occurred in lower limb and $27.16 \%$ of bites in upper limb. This finding is similar to other study of the 81 patients 67 patients applied tourniquet as the first aid..$^{3,5,15,16}$ The use of tourniquets was almost universal. ${ }^{7}$ In this study $64 \%$ of patients have low economic status and $36 \%$ of patients have medium economic status. It may be due to poor housing and their surroundings. Other studies also reported similar results. $^{3,14}$ In our study, most of cases of snake bite is unknown (62\%) and among identified cases most of bite was from Krait $(28 \%)$ and then followed by Cobra and Viper $(5 \%)$. The majority of victim in this study could not identify the biting snake. This finding is similar to other study. ${ }^{3,8,17}$

In this study, pain $(100 \%)$ was the most common clinical presentation followed by ptosis (96.29), respiratory distress $(75.30 \%)$, vomiting $(64.19 \%)$, etc. This find is similar to other study. ${ }^{3,20}$ Clinical features of snake bite may vary according to the species responsible for the bite and the amount of venom injected in the body. ${ }^{7}$ The 
commonest clinical features in the other study was ptosis as it was takes as the gold standard for the confirmation of poisonous neurotoxic bite and start of anti-snake venom. ${ }^{9}$ Out of 81 patients 39 patients were treated with 20-29 vials of ASV and 1 patient was treated with more than 50 vials of ASV. The average number of vials used in each patient was $28 \pm 10$. The previous study suggests that the number of ASV used ranged from 10-38 vials with average of 24.37 vials. $^{3} 1$ vial contain $10 \mathrm{ml}$ of ASV. ASV was administered depending upon the severity of envenomation, body size, body mass, age, amount of venom delivered during bite. ${ }^{5}$

In our study, 46 patients reach less than 4 hour of snake bite and 6 patients reach more than 16 hour of snake bite. $12.5 \%$ of patients were died who reach hospital between 4-7 hours and $50 \%$ of patients were died who reach hospital between 12-15 hours. Mean time to reach hospital after snake bite was 6 hours in this study. Antisnake venom is more effective when used within 4 hours of the snake bite. This finding is quite similar to other previous study. ${ }^{3,11,17}$ The incidence of complication is directly proportional to duration of venom in the blood prior to neutralization by $\mathrm{ASV}^{5}$ Antivenom cannot neutralize bound venom and can be effective only if given early enough to neutralize circulating venom before it bounds to target sites. ${ }^{18}$

In this study it was found that prothrombin time was prolonged in case of snake bite. The normal prothrombin time is $12-16$ second. The maximum patients $(46 \%)$ show prothrombin time between (20-39) seconds and $15 \%$ of patients shows prolongation of prothrombin time more than 100 seconds. This finding is supported by other previous study. ${ }^{1,19}$ In our study we found that victim of hilly region shows more prolongation of prothrombin time i.e. more than 100 seconds. Most of victim of hilly region reported that they are bitten by Green Pit Viper. In all case of Viper bite prothrombin time prolongation was more than 100 seconds that suggests that Viper venom is hemotoxic. Coagulopathy is a significant cause of both morbidity and mortality in these patients either directly or indirectly. ${ }^{1}$ The mean duration of hospital stay was (6 62.86$)$ days while 36 of the 81 patients needed 6-9 days of stay in hospital. This finding was similar to other study. ${ }^{20}$

We found in this study that tetanus toxoid was most commonly used followed by antibiotics (mostly ceftriaxone) for therapeutic intervention. Other drugs include systemic corticosteroids, antihistamines, proton pump inhibitors, adrenaline, atropine, neostigmine, phenytoin, etc. Antivenom is the most effective treatment for snake bite envenomation, but the use of such immunoglobulins has to potential to cause anaphylaxis. As a result, prophylactic treatments including combinations of adrenaline, antihistamine and/or corticosteroids have been used concurrently with anivenom. ${ }^{21,22}$
During this study, we found that the day rains the incidence of snake bite was increased. It may due to during rainy days the holes were filled with water and snake becomes more aggressive they enter inside houses for shelter and in search of prey. Most of bite occur during night in our study. This study is supported by other previous study. ${ }^{7,23-25}$ In this study most patients suffer from secondary wound infection, i.e. cellulitis mostly in case of Cobra bite. This finding was supported by other study also. ${ }^{26-28}$ It is because the oral flora of snake comprises wide range of aerobic and anaerobic microorganisms. ${ }^{26}$ The overall mortality rate in this study was $6.17 \%$. Other study from Nepal reported $3.8 \%$ mortality rate. ${ }^{29}$

\section{CONCLUSION}

Snake bite is still a major problem in Nepal, causing significant morbidity and mortality. There is gross disparity in the management and outcome of snake bite in different hospitals. There is a great need to improve in existing health care conditions for effective management of snake bite, it requires training of the personnel engaged in the emergency health care management, development of national guidelines based on the clinical trials, improving the distribution and easy availability of antivenom. Efforts are needed to develop studies on the epidemiology of snake bite and education of the population at risk. Identification of snake is essential to decide on the type of toxicity and method of treatment to be used. Development and manufacturing of anti-snake venom for local snakes is highly recommended.

\section{Limitation}

As the study was prospective it was totally depending on the patients and their care taker interview and medication chart. Most of patients and their care taker were uneducated so they do not know the medical term and they were unable to explain the exact cause and problem. Some of the patients were not cooperative and they did not fully support the study. Adverse effects of antivenom were not ascertained posing challenges during study. The result of this study was also affected by short duration, small sample size and seasonal variation of snake bite.

\section{Funding: No funding sources \\ Conflict of interest: None declared}

Ethical approval: The study was approved by the Institutional Ethics Committee

\section{REFERENCES}

1. Eslamian L, Mobaiyen H, Makoo BZ, Piri R, Benisi R, Behzad NM. Snake bite in Northwest Iran: A retrospective study. J Anal Res Clin Med. 2016;4(3):133-8. 
2. Kang S, Moon J, Chun B. Does the traditional snake bite severity score correctly classify envenomed patients. Clin Exp Emerg Med. 2016;3(1):34-40.

3. Paudel KM, Paudel VP, Rayamajhi RB, Budhathoki SS. Clinico-epidemiological profile and outcome of poisonous snake bites in children using the WHO treatment protocol in Western Nepal. J Nobel Med College. 2015;4(7):21-5.

4. Garg A, Sujatha S, Garg J, Acharya NS, Parija SC. Wound infections secondary to snakebite. J Infect Developing Countries. 2009;3(3):221-3.

5. Natarajan UM, Natarajan N. A study of snake bite patients with reference to time of delay in management. Scholars J Applied Med Sci. 2016;4(1B):85-8.

6. Kamal RK, Sahu N, Rahul J, Singh SP. Snake Bite, Venom, Anti-Venom Production and Anti- Activity of Medicinal Plants: A Review. Int J Pharm Sci Rev Res. 2015;30(1):227-34.

7. Chaudhary S, Singh S, Chaudhary N, Mahato SK. Snake-bite in Nepal. J Universal Coll Med Sci. 2014;2(3):45-53.

8. Muller GJ, Modler H, Wium CA, Veale DJH, Marks CJ. Snake bite in Southern Africa: diagnosis and management. CME. 2012;30(10):362-82.

9. Poudyal VP, Paudel KM, Rana NB, Adhikari S. A hospital-based study on snake bite poisoning in adults in the western region of Nepal. J Chitwan Med Coll. 2016;6(17):33-8.

10. Inamdar IF, Aswar NR, Ubaidulla M, Dalvi SD. Snakebite: Admissions at a tertiary health care centre in Maharashtra, India. S Afr Med J. 2010;100(7):45658

11. Kshirsagar VY, Ahmed M, Colaco SM. Clinical profile of snake bite in children in rural India. Iran J Pediatr. 2013;23(6):632-6.

12. Monteiro FNP, Kanchan T, Bhagavath P, Kumar GP. Epidemiology of cobra bite in Manipal, Southern India. J Indian Acad Forensic Med. 2005;32(3):2247.

13. Matteucci MJ, Hannum JE, Riffenburgh RH, Clark RF. Pediatric sex group differences in location of snakebite injuries requiring antivenom therapy. J Med Toxicol. 2007;3(3):103-6.

14. Hossain J, Biswas A, Rahman F, Mashreky SR, Dalal K, Rahman A. Snakebite epidemiology in Bangladesh: A national community-based health and injury survey. Health. 2016;8:479-86.

15. Meissner D. WHO Guidelines for the Production, Control and Regulation of Snake Antivenom Immunoglobulins. Blood Products and Related Biologicals Quality and safety: Medicines Essential Medicines and Pharmaceutical policies health systems and services World Health Organization; 2010: 1-134.

16. Fadare JO, Afolabi OA. Management of snake bite in resource-challenged setting: A review of 18 months experience in a Nigerian hospital. J Clinical Med Res. 2012;4(3):39-43.

17. Paudel KM, Sharma S. Study of clinicoepidemiological profile and outcome of poisonous snake bites in children. J Nepal Paediatr Soc. 2012;32(1):47-52.

18. Mustafa M, Fairrul K, IIIzam EL, Firdaus H, Nornazirah A, Mehvish H. Neurotoxicity Related to Snakebite: Treatment and Prevention. J Med Dent Sci Res. 2016;3(10):20-5.

19. Koirala DP, Gauchan E, Basnet S, Adhikari S, BK G. Clinical features, management and outcome of snake bite in children in Manipal Teaching Hospital. Nepal J Med Sci. 2013;2(2):119-24.

20. Reddy PPK and Senthilvelan M. A study of clinical profile of snake bite. Int $\mathrm{J}$ modern res reviews. 2015;3(10):964-8.

21. Fernando M. Guidelines for the management of snakebite in hospital: Produced by the Expert Committee on Snakebite Sri Lanka Medical Association Colombo; 2013: 1-23.

22. Wang JD, Tsan YT, Mao YC, Wang LM. Venomous snakebites and antivenom treatment according to a protocol for pediatric patients in Taiwan. J Venom Anim Toxins incl Trop Dis. 2009;15(4):667-79.

23. Asif N, Akhtar F, Kamal K. A study of ninety snake bite cases at Pakistan air force hospital, Sharkot Pakistan. Pak Armed Forces Med J. 2015;65(3):3338.

24. Sharma SK, Chappuis F, Jha N, Bovier PA, Loutan L, Koirala S. Impact of snake bites and determinants of fatal outcomes in southeastern Nepal. Am J Trop Med Hyg. 2004;71(2):234-8.

25. Pandey DP, Vohra R, Stalcup P, Shrestha BR. A season of snakebite envenomation: presentation patterns, timing of care, anti-venom use, and case fatality rates from a hospital of southcentral Nepal. J Venom Res. 2016;7:1-9.

26. Tagwireyi D, Nhachi CFB, Ball DE. Snakebite admissions in Zimbabwe: Pattern, clinical presentation and management. Central Afr J Med. 2011;57(5/8):17-22.

27. Ghosh S, Mukhopadhyay P, Chatterjee T. Management of snake bite in India. J Assoc Physicians India. 2016;64:11-4.

28. Alizadeh AM, Moghaddam HH, Zamani N, Rahimi $\mathrm{M}$, Mashayekhian $\mathrm{M}$, Domeneh $\mathrm{BH}$, et al. The protocol of choice for treatment of snake bite. Advances Med. 2016: 1-5.

29. Hansdak SG, Lallar KS, Pokharel P, Shyangwa P, Karki P, Koirala S. A clinico-epidemiological study of snake bite in Nepal. Trop Doct. 1998;28(4):223-6.

Cite this article as: Chaudhary MK, Gupta LK, Chand LB, Chaudhary R, Ranpal S. A prospective study on clinico-epidemiological profile and outcome in management of poisonous snake bite. Int $\mathrm{J}$ Basic Clin Pharmacol 2020;9:695-700. 